\title{
A Study on the English Journals Published by Commercial Press of China
}

\author{
Huanqi Ji, a , Xie Zhang ${ }^{1, b}$ \\ ${ }^{1}$ College of Humanities, Sichuan Agricultural University, Ya' an 62500, China \\ ajoe0919@126.com, bbecky0919@126.com
}

\begin{abstract}
Keywords: Commercial Press of China, English Journal, Feature
Abstract. Four English Journals had been published by Commercial Press of China in the early twentieth century and the issuing background and theme of the four journals are probed. These four journals have three prominent features: first, they were edited by famous scholars; second, they have a rich content concerning English teaching and learning; third, they placed a special stress on the interaction with their readers, thus making a profound influence on disseminating English knowledge as well as popularizing English education in China.
\end{abstract}

\section{Introduction}

As a most prominent domestic press in China, Commercial Press of China issued four English journals during the early time of twentieth century. These four journals are known as English Student, Supplement to English Student, English Weekly and Supplement to English Weekly, among which English Student and English Weekly have been listed as "Ten Major Journals" of the Commercial Press. Although these four journals had made great contribution to propagating English knowledge and popularizing English education in China, little attention has been paid to the study of them so far and records of them are even misleading. In his Memoir of 100-Year-Old Commercial Press, Chen Yingnian[1], who was once the director of Commercial Press History Office, mistook Hu Zhemou, the chief editor of English Student, as Zhou Youjin, the chief editor of English Weekly. Similarly, Mao Dun[2], a famous literary translator and writer in China, also made the same mistake when recalling his work in the Compiling and Translating Office of Commercial Press in his autobiography. The renowned Shanghai Publishing Encyclopedia just included English Student and English Weekly without any entry of Supplement to English Student and Supplement to English Weekly. Apart from Cheng Yingnian and Mao Dun, famous English compilers or teachers like Xie Juzeng[3], Zhou Yueran[4] and Ge Chuangui[5], etc, also mentioned those English journals in their books, but failed to elaborate in detail. Based on the previous records and studies and through examining the original journals, this paper proposes new insights into the prominent features and social impact of the four English journals.

\section{Issuing Background and Aim of the Journals}

Founded in Shanghai in 1897, Commercial Press of China was first a printing factory, specializing in printing commercial account book and advertisements. At the same time, it also took orders for printing Bible, Journal of Foreign Affair and Scientific Review. In 1902, a compiling and translating office was established to "compile and translate all kinds of books written both in Chinese and foreign languages”. During its early time, a compiling and translation department was set up with an English section attached to it under the office. In 1903, Zhang Yuanji, a renowned educator, was appointed to head the compiling and translating office. With Zhang's direction, the English section upheld the notable principle that "We shall take responsibility to assist in education in China", and strove to compile and publish English textbooks, dictionaries and English journals. It is reputed to launch the first English correspondence school in China. As the business of Commercial Press grew, the compiling and translating office successively established committee of English-Chinese dictionary, English Student press, English Weekly press and English correspondence education board. 
English Student and its supplement were launched in January 1915, while English Weekly and its supplement in October 1915. The former was a monthly journal and stopped in 1927; the latter was a weekly journal and ended in 1937. As the journals were issued at a time when the First World War was breaking out, Chinese industry and commerce were developing at a golden time. English as a communication tool played a very important role in growing communication with the outside world. Although the 1913 Education Code decreed by the Chinese government required primary schools offer English course according to their own practical situation and high schools included English as a foreign language in the curriculum: "Foreign language teaching shall focus on English with French, German and Russian as selective ones if necessary.” [6] Nevertheless, the foreign language teaching in the primary and high schools were barely satisfactory because there had been a great difference in foreign language teaching between the coast regions and inner places, big cities and small and medium cities, cities and countryside. As a matter of fact, "most school could hardly offer foreign language teaching and foreign language teachers were in great demand. The coast regions only were often in a position to give foreign language lessons. In general, the foreign language teaching in primary and secondary schools are scarcely effective." [7] Apart from some missionary schools and special English school which could help students learns English, there had been a greater demand yet to meet with the development of industry and commerce in China. Recognizing such an actual social reality and at once seizing it as an opportunity, editors of English section in the compiling and translating office undertook to start the above-mentioned four English journals in an effort to assist English teachers, students as well as English lovers, who could not afford to learn English in school, in their teaching and study. Both English Student and English Weekly state such an aim clearly in their editorial of the first issue. The editorial of English Student goes like this:

There is now a strong tendency in the schools of the West to supplement widely the work in the class-room with additional reading matter, so as to enrich the contents of the subject matter and make the work interesting. In recognition of the need for such supplementary reading matter for Chinese students of English language, the Commercial Press has long thought of issuing an English magazine. Now we are able to publish "The English Student", the aim of which is to help Chinese students of the English language. This monthly being the first of its kind published in China, "The English Student” purposes to provide our readers with good reading material in English. It will explain the most difficult parts of some text-books, suggest new methods for reading, and introduce the students to good literature. [8]

As for English Weekly, the editorial in the first issue says:

We are today introducing ourselves in this Weekly to our readers, to whom we offer our services in their English study. Since our announcement of the publication of this magazine appeared, many letters have come in from the student class and others bearing their good wishes, which have cheered us. We shall spare no pains and time to make the English Weekly helpful to them. We do not wish to say anything regarding its contents, but leave it with our readers to say as to how useful and instructive they are. [9]

It is quite clear to see that both English Students and English Weekly have a common aim to fulfill, that is, to help Chinese readers with their English. There is no doubt that he two supplements to the English Students and English Weekly will assist in achieving the common goal set for their main journals.

\section{Editing Features}

\subsection{Prominent Editing Staff Members}

Editors of the four English journals were composed of prominent figures, which is also an important feature of the English section in the compiling and translating office. As one of earliest section set up in the compiling and translating office, it consisted of a great number of scholars proficient in English as well as English education experts, among whom Zhou Yueran could be regarded as one of the most important because he, a graduate from Fudan University, had worked for 
the Commercial Press of China for more than 30 years since he entered the English section in January 1915. Zhou Yueran wrote in his article Commercial Press and I:

When I worked in the Commercial Press, it was entering it developmental momentum. Apart from the director Kuang Fuzhuo, there were Xu Runquan, Gan Yonglong, Wu Buyun, Zhang Shuliang, Qiu Peizhi, etc in the English Section. As the business grew later on, English Weekly was issued, English correspondence school was set up and English educational books are compiled. More staff members like Guo Bingwen, Jiang Mengling, Chen Zhusu, Li Peien, Shao Peizi, Long Zhibin, Zhou Xisan, Ping Hailan, Zhou Youjin, Chen Bulei, Wu Zhijue, and Huang Fangshu also joined the English section.[4]

As a matter of fact, there were far more editors than was mentioned by Zhou Yueran. Going through the four journals can find many other editing staff. Firstly, there were three chief editors in succession for the English Student and they were Wu Jigao, Ping Hailan and Hu Zhemeng. Other editors included Kuang Fuzhuo, Zhang Shiliu, Guo Bingwen, Zhou Yueran, Gan Zuolin, Huang Fangshu, Lipeien, Su Zhaolong, Jiang Menglin, Zhou Youjin, Zhou Xisan, Cheng Chengzu, Zhou Houkun, Jiang Zhengyi, Yan Wanzi, Du Fengyi, Yan Jingyu, Ji Shichang, Qian Zhixiu, Xia Zenyin, Liu Zhixin, Gu Runqin, Xie Fusheng, Wang Buxian, Ni Haosen, Liu Linsheng, Kuang Guanglin, Wu Guangpei, Tang Mingshi, Dong Shoupeng, etc. Secondly, there were two chief editors for English Weekly and they were Zhang Shiliu and Zhou Youjin. Other editors were Kuang Fuzhuo, Zhou Yueran, Huang Fangshu, Ping Hailan, Su Zhaolong, Gu Runqin, Li Peien, Xia Zenyin, Liu Zhixin, Hu Zhemou, Wang Buxian, Ni Haosen, Gong Wenfang, Li Junhui, Hua Chao, Gui Yu, Qian Zhong, $\mathrm{Xu}$ Shiguang, Ge Chuangui, etc. The standing editing staff members were mainly Kuang Fuzhuo, Zhou Yueran, Ping Hailan, Hu Zhemou, Guo Bingwen, Huang Fangshu, Li Peien, etc. And the number of other editing staff members fluctuated as time wen on. Most of them took on several roles for they had to compile English textbooks, issue English journals and function as a teacher in the English correspondence school, marking test papers.

Editors of the four English journals embodied a strong academic relationship. In other words, they were more or less related to each other through college, academic group, classmates, or association. The major editors of the English section came from prominent institutions, graduating from famous universities both home and abroad. For instance, Wu Jigao graduated from translation department of Nanyang College, the predecessor of the famous Shanghai Ji aotong University, which was once headed by Zhang Yuanji, the director of the compiling and translating office. Gan Zuolin, Zhang Shiliu and Ping Hailan also graduated from the same college. Ping Hailan had been to Tokyo Special English College to further his study. When Ping Hailan was back in China, he joined to set up Datong College and Hailan Special English College in Shanghai, hence being credited as the "English teaching forerunner in China”. Hu Zhemou and Mao Dun were classmates and graduated from Peking University. Zhou Yueran graduated from Fudan University. Xu Runquan, Jiang Menglin and Gu Runqin graduated from St. John's University in Shanghai. Kuang Fuzhuo, the director of English section, and Guo Bingwen studied in the same Columbia University in the United States and both had a doctorate degree. In addition, Ge Chuangui, the famous Linguist, was once a student enrolled in the English correspondence school of the Commercial Press. Therefore, the English section had many talented personnel, which could be regarded as the best editing staff in China.

3.2 Profuse Learning and Teaching Material

The English journals provided rich contents for the readers in each issue. As is written in the editorial of English Student, "it embraces the following sections: editorial, literature, composition, conversation, letter-writing, translation, novels and stories, proverbs and maxims, questions and answers, current events, science notes, etc.” [8] Therefore, in order to fulfill the aims of those English journals, editors spared no pains to offer English learning and teaching material as much as possible, which roughly fell into two major focuses: one was intended for the students and the other for the teachers.

For the students, editors started from the basic level like English pronunciation, words learning, to the intermediate level such as sentence structure, conversation, and then to the high level like English writing, literary translation, literature analysis. English Weekly devoted special place for the 
commercial English which was in great demand at the time. Editors offered detailed information in relation to foreign trade procedures which included business letter writing, taking and placing order, customs tax and rules, foreign exchange rate, total cost, retail price, wholesale price, commercial training, draft, promissory note, banking, etc.

For the teachers, it is noteworthy to see that English Student endeavored to improve English teaching level in China considering the low-quality English teaching all over China at the time. From the second issue on, it carried Zhou Yueran's Notes on the Teaching of English in 9 consecutives issues. Zhou Yueran stressed that cultivating students' ability to read, write and speak were three essential points in English teaching classes. And Zhou dwelt on seven aspects on how to effectively conduct English teaching classes from the perspective of teacher's quality, pedagogy, teaching material, classroom management, phonetics, grammar and literary reading. [10] Moreover, in another paper written by Zhou Yueran, he proposed ten subjects that an English teacher needed to be fully prepared as follows: Elements of Phonetics, Orthography, Etymology and Syntax, Synonyms, Words and Idioms, English Literature, Prose and Poetical Works, Translation, Composition, Conversation, and Method of Teaching. [11] Meanwhile, English Student also carried Questions on Teaching contributed by American scholar Franklin B. Dyer who proposed 61 questions altogether on teachers' character, classroom setting, class management, teaching material, pedagogy, teaching aid tools. [12] Those questions were quite useful in helping English teachers figure out ways to improve their English classes.

The differences between English Student and English Weekly are noticeable. English Student placed special stress on building a solid English knowledge foundation, and there were rich contents of both language teaching and learning and it was better fit for senior high school and college. Whereas English Weekly was mainly devoted to English language usage, particularly in the commercial English, hence it was more suitable for primary and junior high school.

3.3 Active Interaction between Editors and Readers

The English journals adhered to the principle of active interaction between editors and readers. Just as was stated in the first editorial of English Student:

We hope that teachers and those who are interested in the teaching of English will send us contributions and suggestions as to how to make the magazine of value to a large circle of earnest students. We should like our students of English to feel that this is their magazine. We should like to know from them how we can make it serve their interests. We should like to have them send us samples of their composition work f for publication. [8]

Such interaction was mainly achieved through "Questions and Answers", "Prize Competition”, “Readers” Letters” and "Readers' Contribution”. Firstly, “Questions and Answers” was intended to help solve various kinds of questions that readers might encounter either in English teaching or English learning. Secondly, some of the readers were having a job in certain business; therefore "Readers' Letters" became an important channel to help solve their problems at work. More importantly, in order to motivate readers' English learning to a higher level and get a dynamically full picture of readers' mastery of English language, both English Student and English Weekly would hold "Prize Competition" in a few forms like English-Chinese translation, Chinese-English translation, composition, and etc. Winners of first, second and third prizes would be rewarded with prize money and book gifts.

Compared with other magazines published by Commercial Press, those English journals did not deliberately carry out a one-way communication and editors did not make readers be constant passive receivers. But rather, they encouraged active responses from students, teachers and even workers in companies, thus succeeded in narrowing the distance between them and the readers.

\section{Social Influences}

Commercial Press of China was the first to publish English journal in China and supplied a wealth of English knowledge for the readers with the help of its strong editing team, and had enjoyed wide applause from all walks of life. In the own words of English Student, "Since the publication $\mathrm{f}$ this 
journal, it has been well received by all the readers and has been commended as the only journal to study English.” The domestically renowned journal called Science recommended English Student as "one which endeavors to push forward English study on the part of Chinese students and common English readers. As the first English journal in China, English Student is also an excellent aid in students' English class.” [13]

As a matter of fact, English Weekly was also the only English journal circulated in China. Regarding its social influences, the well-known Chinese Daily News of Shanghai commended it as "one particular magazine and it develops a close relationship with the readers through questions and answers. As over 20,000 copies are sold each week, it enjoys great popularity not only among domestic readers but also among overseas Chinese in Japan, U.K., France and Netherlands”. [14] As a result, the Chinese Ministry of Education issued an official comment in favor of both English Student and English Weekly, stating that these journals are "concise and clear and help to supplement what is weak in English teaching in school. They are an excellent reference for English teachers as well as English students.” [15]

\section{Conclusions}

The English teaching system was rather incomplete in China in the early twentieth century for there had been a severe lack of both English teachers and English teaching materials. In order to meet the social demand for English learning, the Commercial Press of China took the initiative to launch the first four English journals in China. With a strong editing team, rich contents concerning English teaching and learning as well as a special stress on interaction between editors and readers, the four journals played an important role in assisting English teaching and learning, and helped to produce lots of competent English employees for the economic and social development of China. These journals are also of great usefulness and significance in promoting the current English journals in China to a higher level as well as for the research of English education in China.

\section{Acknowledgements}

This research work was supported by the General Project of Humanity and Social Science Sponsored by Ministry of Education of China under Grant No. 15YJC740043.

\section{References}

[1] Chen Yingnian. Memoir of 100-Year-Old Commercial Press [A]. 100-Year-Old Commercial Press (1897-1987) [C]. Beijing: Commercial Press, pp. 590, 1998.

[2] Mao Dun. My Life as a Student [A]. The Road I Walked [C]. Beijing: People’ s Literary Press, pp.113, 1997.

[3] Xie Juzen. Memoir of Hanfen Building [A]. Essays (Vol. 7) [A]. Guangzhou: Guangzhou People’ s Press, pp. 68, 1980.

[4] Zhou Yueran. Commercial Press and I [A]. 95-Year-Old Commercial Press (1897-1992) [C].

Beijing: Commercial Press, pp. 167, 1992.

[5] Ge Chuangui. Commercial Press and I [A]. 95-Year-Old Commercial Press (1897-1992) [C].

Beijing: Commercial Press, pp. 355, 1992.

[6] Yu Shusheng. A General History of Chinese Education System (1911-1949) [M]. Jinan: Shandong Educational Press, pp22, 2000.

[7] Li Chuansong, Xu Baofa. A History of Foreign Language Teaching in Modern China [M]. 
Shanghai: Shanghai Foreign Language Education Press, pp29, 2006.

[8] Editorial [J]. English Student 1(1), pp. 1-3, 1915.

[9] Editorial [J]. English Weekly 1(1), pp. 1-2, 1915.

[10] Zhou Yueran. Notes on the Teaching of English [J]. English Student, 12(2-10), pp.31, pp.135, pp.209, pp.277, pp.353, pp.423, pp.497, pp.575, pp.643, 1916.

[11] Zhou Yueran. Things Required of a Teacher of English [J]. English Student, 17(5), pp.350-352, 1916.

[12] Franklin B. Dyer. Questions on Teaching [J]. English Student, 15(3), pp.205-208, 1916.

[13] Introduction of English Student [J]. Science, 1(1), pp.145, 1916.

[14] Introduction of English Weekly [N]. Chinese Daily News, October 15, 1916.

[15] Reply of Ministry of Education of China [J]. English Weekly, 8(7), pp. 420, 1916. 